\title{
Rancangan Web Information System Asset Management Pada PD.BPR Kerta Raharja Cabang Balaraja
}

\author{
Mulyati ${ }^{1}$ \\ Yulianto $^{2}$ \\ Andika Supriyana ${ }^{3}$ \\ Sistem Informasi Manajemen, Perguruan Tinggi Raharja \\ E-mail:mulyati@raharja.info ${ }^{1}$; yulianto@ raharja.info ${ }^{2}$; andika.supriyana@.com ${ }^{3}$
}

\begin{abstract}
ABSTRAK
Setiap perusahaan membutuhkan informasi yang cepat dan akurat, salah satunya adalah informasi mengenai aset yang dimiliki oleh suatu perusahaan. Aset merupakan barang atau benda yang terdiri dari benda yang bersifat bergerak dan benda yang bersifat tidak bergerak yang dimiliki oleh perusahaan. PD.BPR Kerta Raharja merupakan Perusahaan Daerah milik Pemerintah Kabupaten Tangerang bersama-sama Pemerintah Provinsi Banten, Provinsi Jawa Barat dan PT Bank Jabar Banten yang bergerak dalam pemberian kredit pada masyarakat. Yang dimana saat ini dalam proses pencatatan data aset masih menggunakan aplikasi Ms. Excel, dimana masih dapat terjadi salah input data aset dan bisa saja data hilang dari penyimpanan. Tujuan penelitian ini adalah untuk merancang sistem informasi manajemen aset pada PD.BPR Kerta Raharja Cabang Balaraja. Penelitian dilakukan dengan cara observasi, wawancara dan studi pustaka. Analisa menggunakan metode analisis SWOT (Strenghts, Weaknesses, Opportunities, Threats). Kemudian menggunakan UML (Unified Modeling Language) untuk menggambarkan prosedur sistem yang berjalan, menggunakan bahasa program PHP dan menunggunakan MySQL sebagai database yang dibangun. Hasil akhir yang dicapai pada sistem informasi manajemen aset memiliki kelebihan dalam membantu user untuk memperoleh informasi yang lebih cepat dan akurat, mulai dari pendataan sampai pembuatan laporan.
\end{abstract}

Kata kunci : Manajemen Aset, Data, Analisis 


\section{ABSTRACT}

Every company needs fast and accurate information, one of them is information about assets that are owned by a single company. The asset is an item or object that is made up of objects that are in motion and an object that is not moving, owned by the company. PD. BPR Kerta Raharja is the company Governmentowned area of Tangerang Regency Government together Banten, West Java and PT Bank Jabar Banten in the granting of credit on the society. Which is currently in the process of recording data assets are still using Ms application. Excel, where it still can occur is wrong data input and data assets missing from storage. The purpose of this research is to design information systems asset management in PD.BPR Kerta Raharja Balaraja Branch. Research done by observation, interviews and literature study. Analysis using the method of SWOT analysis (Strenghts, Industry, Opportunities, Threats). Then use the UML (Unified Modeling Language) to describe the procedure in a system that is running, using the programming language PHP and the MYSQL database as the menunggunakan was built. The end results were achieved at asset management information system has advantages in helping the user to obtain information more quickly and accurately, from logging to the making of the report.

Keywords: Asset Management, Data, Analysis

\section{PENDAHULUAN}

Di masa yang serba cepat ini, penggunaan komputer dan sistem-sistemnya sudah menjadi kebutuhan yang utama dalam rangka meningkatkan kinerja suatu instansi atau perusahaan. Setiap proses manual dari instansi atau perusahaan tersebut dapat digantikan dengan sistem yang terkomputerisasi karena penyediaan informasi yang lebih canggih serta dapat mendukung proses pengambilan keputusan yang dilakukan oleh manajemen.

Namun pada kenyataannya masih banyak instansi atau perusahaan yang menggunakan sistem yang belum terkomputerisasi dengan baik, sama halnya yang terjadi di Perusahaan Daerah Bank Pengkreditan Rakyat (PD.BPR) Kerta Raharja Cabang Balaraja. PD.BPR Kerta Raharja merupakan Perusahaan Daerah milik Pemerintah Kabupaten Tangerang bersamasama Pemerintah Provinsi Banten, Provinsi Jawa Barat dan PT Bank Jabar Banten yang bergerak dalam pemberian kredit pada masyarakat. Dalam kegiatan membuat laporan manajemen data aset saat ini, PD.BPR Kerta Raharja Cabang Balaraja belum memiliki sistem yang terintegrasi dalam pengelolaan manajemen data aset, pengelolaan masih menggunakan 
aplikasi dekstop yang dioperasikan oleh satu komputer dengan menggunakan aplikasi $M s$. Excel. Data-data yang ada dikelola dalam bentuk arsip-arsip, sehingga relatif lambat untuk melakukan koreksi dan pengawasan terhadap data aset dan bisa menimbulkan kendala dalam kepraktisan dan efisiensi dalam hal pengecekan. Dengan menggunakan sistem aplikasi, semua dapat dilakukan dengan proses yang mudah dan cepat serta lebih efektif dan efisien karena dengan menggunakan sistem aplikasi semua proses akan berjalan sangat cepat dan data yang tersimpan akan aman.

Berdasarkan masalah-masalah di atas maka perlu adanya pembenahan terhadap sistem yang sedang berjalan dan pengembangannya harus disesuaikan dengan kebutuhan saat ini dan masa yang akan datang.

Maka diambil judul "Perancangan Sistem Informasi Manajemen Aset pada PD.BPR Kerta Raharja Cabang Balaraja”

\section{PERMASALAHAN}

Banyak instansi atau perusahaan yang menggunakan sistem yang belum terkomputerisasi dengan baik, sama halnya yang terjadi di Perusahaan Daerah Bank Pengkreditan Rakyat (PD.BPR) Kerta Raharja Cabang Balaraja. PD.BPR Kerta Raharja merupakan Perusahaan Daerah milik Pemerintah Kabupaten Tangerang bersama-sama Pemerintah Provinsi Banten, Provinsi Jawa Barat dan PT Bank Jabar Banten yang bergerak dalam pemberian kredit pada masyarakat. Dalam kegiatan membuat laporan manajemen data aset saat ini, PD.BPR Kerta Raharja Cabang Balaraja belum memiliki sistem yang terintegrasi dalam pengelolaan manajemen data aset, pengelolaan masih menggunakan aplikasi dekstop yang dioperasikan oleh satu komputer dengan menggunakan aplikasi $M s$. Excel.

\section{METODOLOGI PENELITIAN}

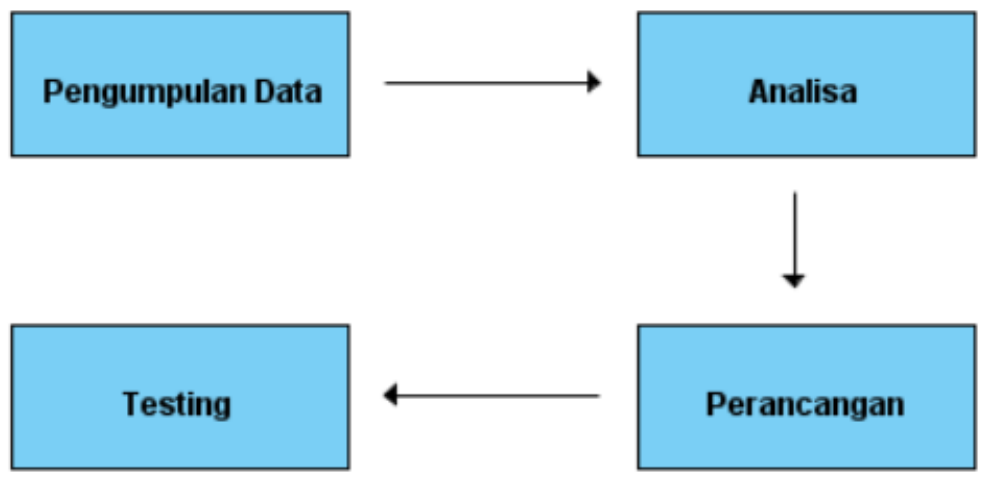


1. Pengumpulan Data, yaitu melakukan pengamatan langsung terhadap pengelolaan proses dan disertain tanya jawab dengan narasumber untuk mendapatkan informasi.

2. Analisa, setelah melakukan proses pengumpulan data, maka data akan diolah supaya mendapatkan suatu hasil akhir yang bermanfaat untuk penelitian.

3. Perancangan, selanjutnya melakukan suatu perencanaan untuk membuat sebuah penelitian sesuai prosedurnya.

4. Testing, pengujian suatu aplikasi/software yang telah dibuat agar mendapatkan suatu nilai akhir.

Berikut ini adalah daftar literature review yang digunakan dalam penelitian ini:

1) Penelitian yang dilakukan oleh Tities Sumunaring Tyas dan Ali Tarmuji pada tahun 2013 dengan judul "Perancangan Enterprise Architecture Planning (EAP) Pada Proses Manajemen Aset Dengan Zachman Framework (Studi Kasus Divisi Manajemen Fasilitas PT> XYZ)”. Metodologi yang digunakan dalam perancangan arsitektur enterprise disini adalah Enterprise Architecture Planning (EAP) dengan Zachman Framework yang mengacu baris pertama dan kedua yang merupakan perspektif perencana dan pemilik, serta 3(tiga) kolom pertama yaitu kolom Data, Fungsi dan Jaringan. Hasil perancangan yang telah dibuat meliputi arsitektur data, arsitektur aplikasi dan arsitektur teknologi, portofolio aplikasi. Dari penelitian ini dihasilkan blueprint (cetak biru) perancangan Enterprise Architecture Planning (EAP) dari manajemen aset.

2) Penelitian yang dilakukan oleh Elmi Fauziati pada tahun 2016 dengan judul “Perancangan Sistem Informsi Manajemen Aset Di Kecamatan Pasar Kemis". Metode perancangan menggunakan UML (Unified Modeling Language), bahasa pemrograman ASP VisualBasic Script, IIS (Internet Information Services) tool yaitu paket perangkat lunak ke dalam satu buah paket, database untuk SQLServer, Adobe Dreamweaver CS5 untuk mendesign web yang akan dibuat. Hasil akhir yang dicapai pada sistem informasi manajemen aset mempunyai kelebihan dalam membantu user untuk memperoleh informasi lebih cepat, tepat dan akurat mulai dari pendataan sampai pembuatan laporan.

3) Penelitian Penelitian yang dilakukan oleh Marco Greco Livio dan Cricelli Michele Grimaldi pada tahun 2013 dengan judul "A Strategic Management Framework Of Tangible And Intangible Assets”. Penelitian ini membahas tentang manajemen yang strategis dengan memperhatikan dampaknya. 
4) Penelitian yang dilakukan oleh Ronald N. Kahn dan Michael Lemmon pada tahun 2016 dengan judul “Asset Manager's Dilemma: How Smart Beta Is Disrupting the Investment Management Industry”. Penelitian ini membahas tentang melakukan manajemen aktif namun dengan biaya yang lebih rendah.

5) Penelitian yang dilakukan oleh Rika Yunitarini pada tahun 2014 dengan judul "Sistem Informasi Manajemen Tata Kelola Aset. Informasi Perhotelan pada Hotel Mahkota Lamongan". Sistem Informasi Hotel Mahkota yang dibuat menggunakan Microsoft Visual Basic sebagai bahasa pemrograman serta menggunakan database SQL server. Hasil Akhir Sistem informasi ini memiliki beberapa fitur yang dapat memudahkan aktifitas pengelolaan. Informasi di hotel Mahkota, antara lain aktifitas front office dan back office. Dengan adanya sistem ini, diharapkan mampu meningkatkan manajemen yang baik, sehingga tercipta hotel dengan pelayanan yang lebih baik.

6) Penelitian yang dilakukan oleh Gentisya Tri Mardiani pada tahun 2013 dengan judul "Sistem Monitoring Data Aset dan Inventaris PT Telkom Cianjur Berbasis Web". Sistem Monitoring ini berbasis web, menggunakan bahasa pemrograman PHP dan Local Area Network (LAN) dan Desktop Support. Hasil akhir dengan aplikasi ini memudahkan dalam proses pengolahan dan pembuatan laporan data aset dan pengolahan distribusi perangkat kepada karywan, serta aplikasi mampu mengurangi kemungkinan adanya duplikasi data.

7) Penelitian yang dilakukan oleh Fitria Sani pada tahun 2014 dengan judul "Perancangan Sistem Informasi Manajemen Aset dan Inventaris SMK N 7 Padang”. Rancangan sebuah sistem informasi yang berbasis database dan alat pengembangan sistem dengan Flow Map System, Context Diagram, dan Activity Diagram. Hasil akhir dengan adanya sistem ini maka manajemen pengelolahan aset dan inventaris lebih terstruktur dan terarah serta penyimpanan datanya terjamin, aman, dan tidak banyak memakai waktu.

Setelah melakukan peninjauan dari 7 Literature Review yang ada, telah banyak penelitian mengenai manajemen yang berhubungan dengan Sistem Informasi Manajemen Aset.

\section{HASIL DAN PEMBAHASAN}

Menyajikan hasil analisis data akhir, bukan data mentah yang belum diolah. Hasil perhitungan dan pengujian lainnya dapat ditampilkan pada bagian ini yang ditampilkan hanyalah hasil perhitungan yang penting untuk diketahui. 


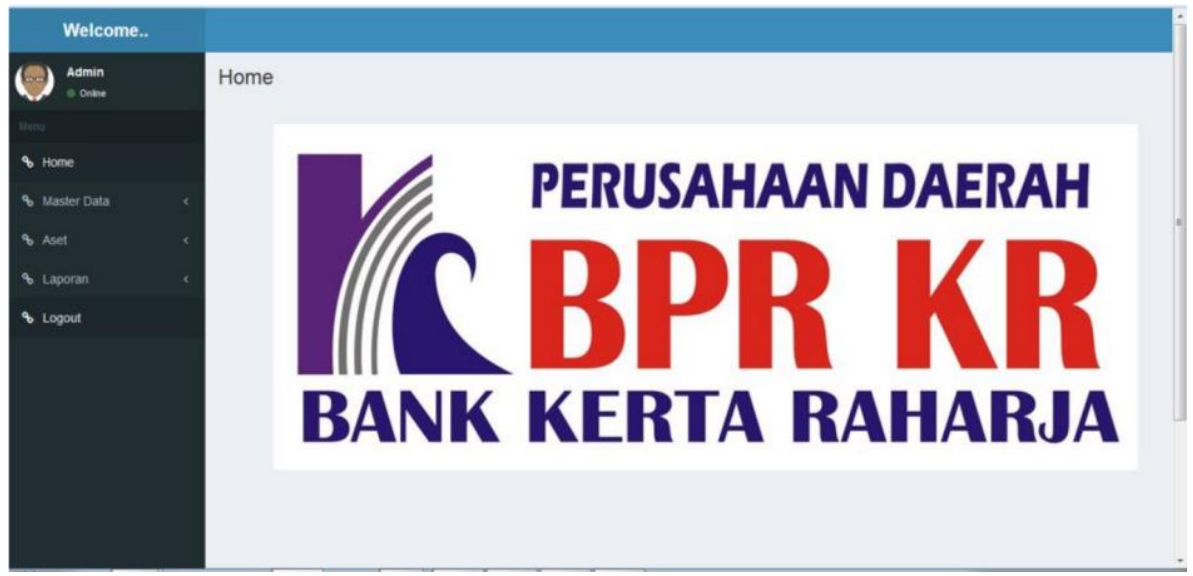

Gambar 2. Tampilan Web Halaman Utama

Gambar di atas merupakan Halaman Utama dari Manajemen Aset. Sistem yang sudah tersedia di dalam halaman utama dengan logo nama perusahaan agar memudahkan seseorang untuk mengakses data.

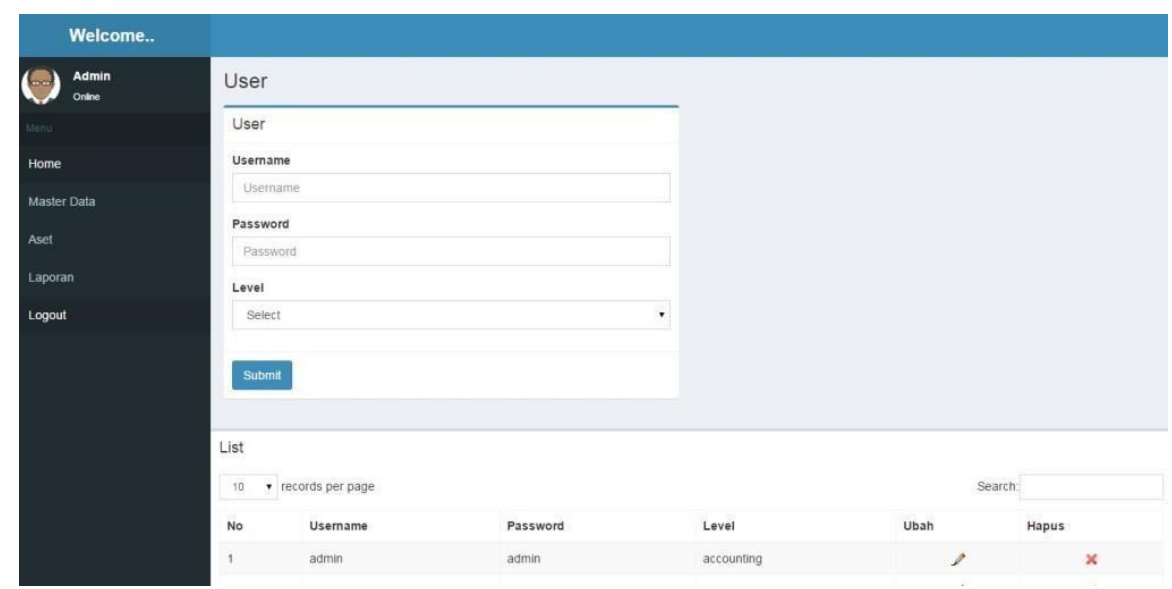

Gambar 3. Tampilan Web Menu User

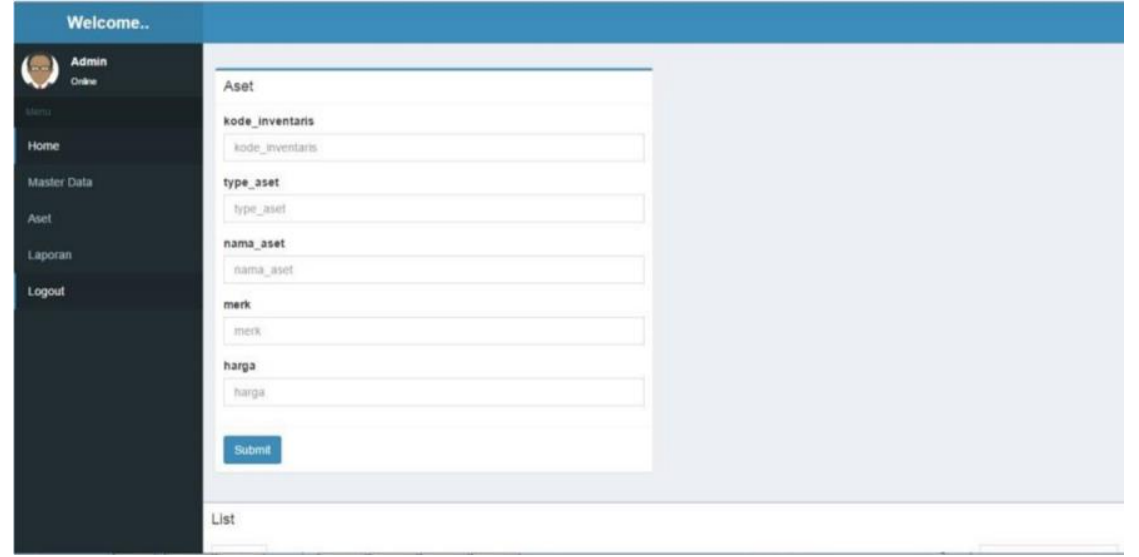

Gambar 4. Tampilan Web Menu Aset 


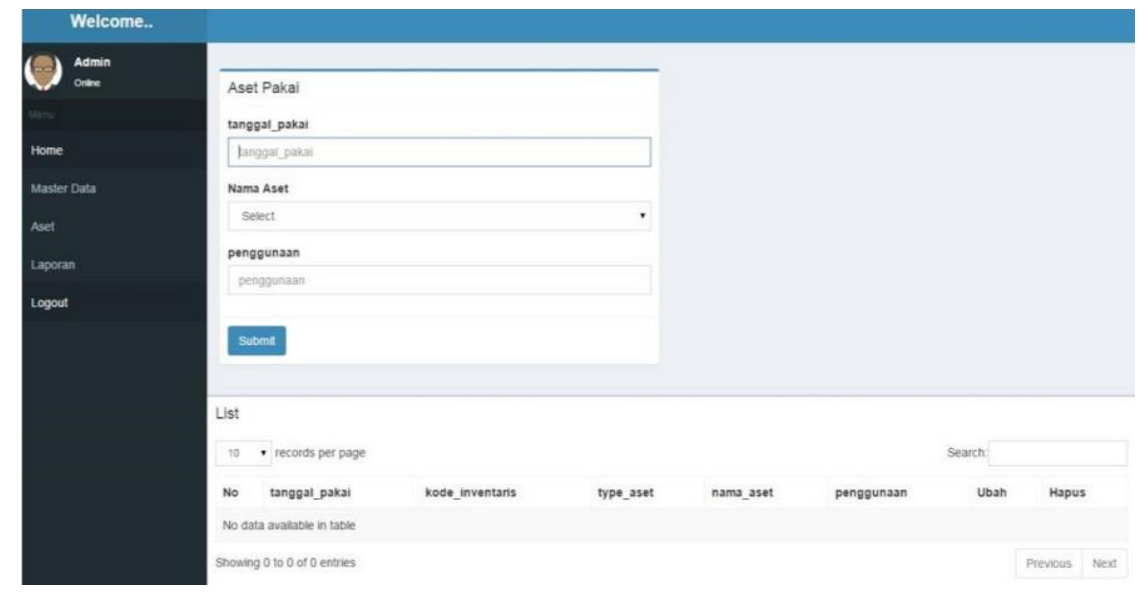

Gambar 4. Tampilan Web Menu Aset Pakai

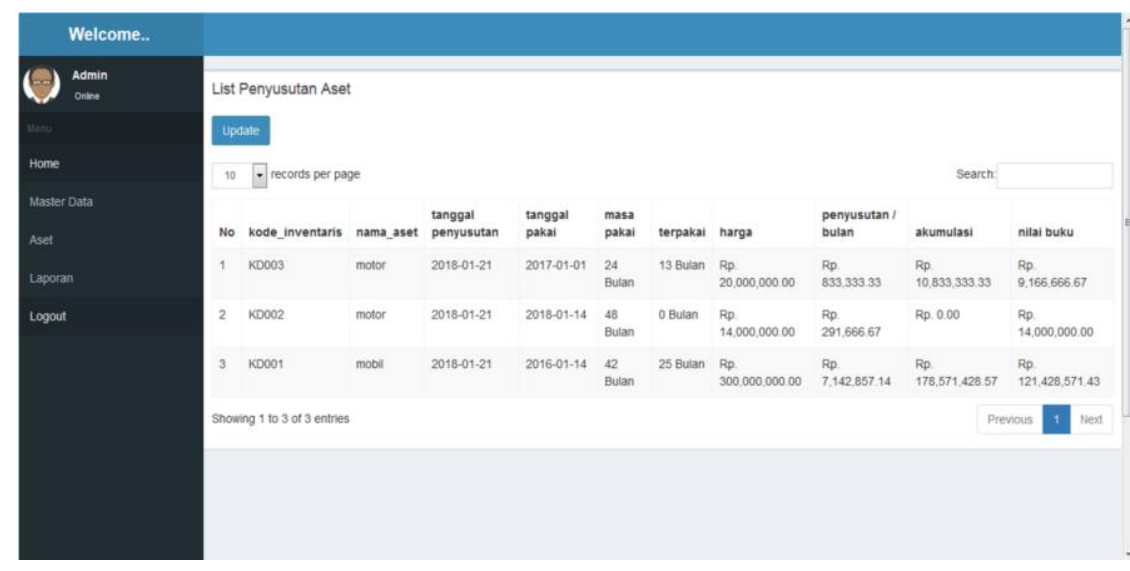

Gambar 5. Tampilan Web Menu Penyusutan

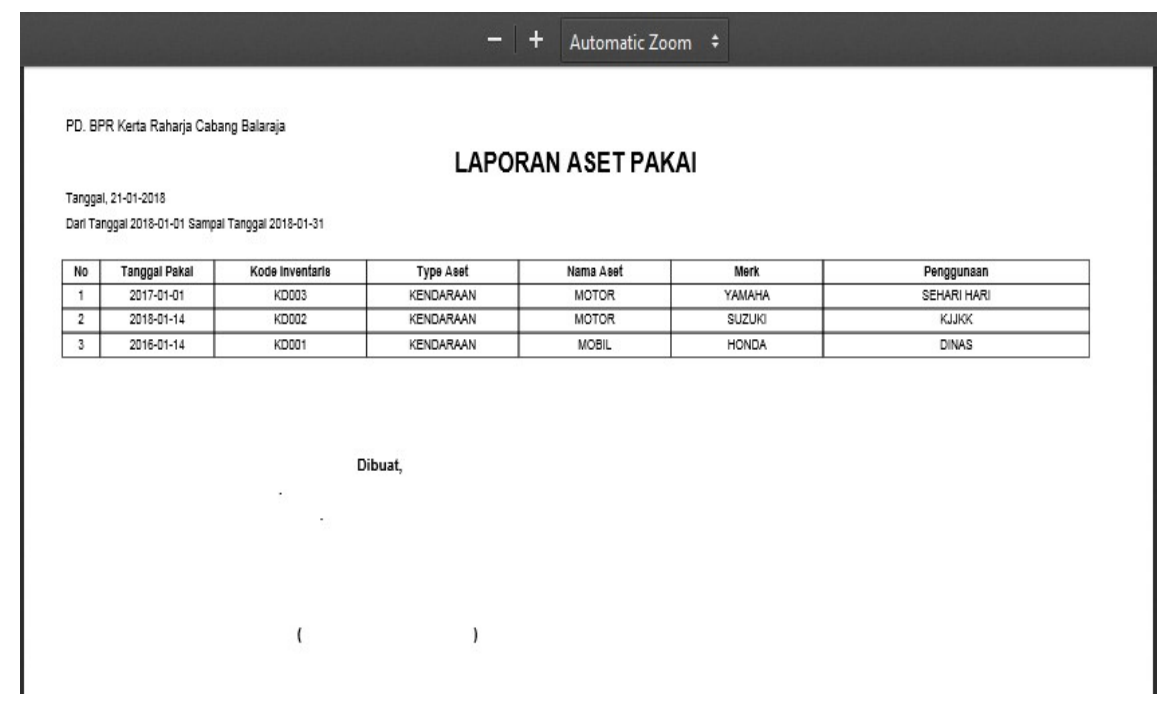

Gambar 6. Tampilan Web Menu Laporan Aset Pakai 


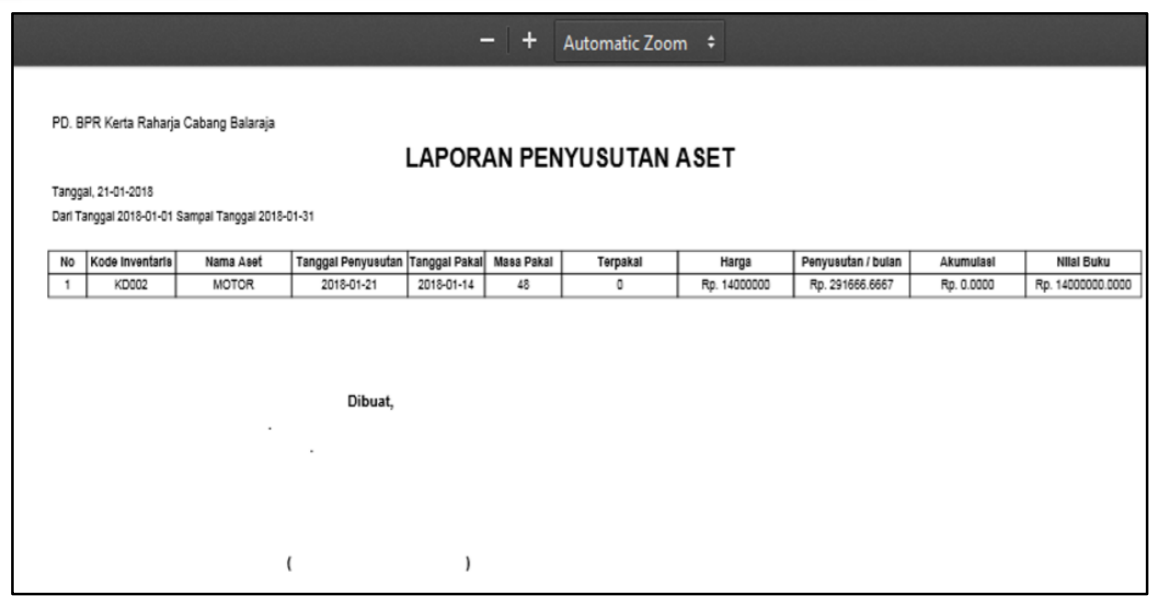

Gambar 7. Tampilan Web Menu Laporan Penyusutan

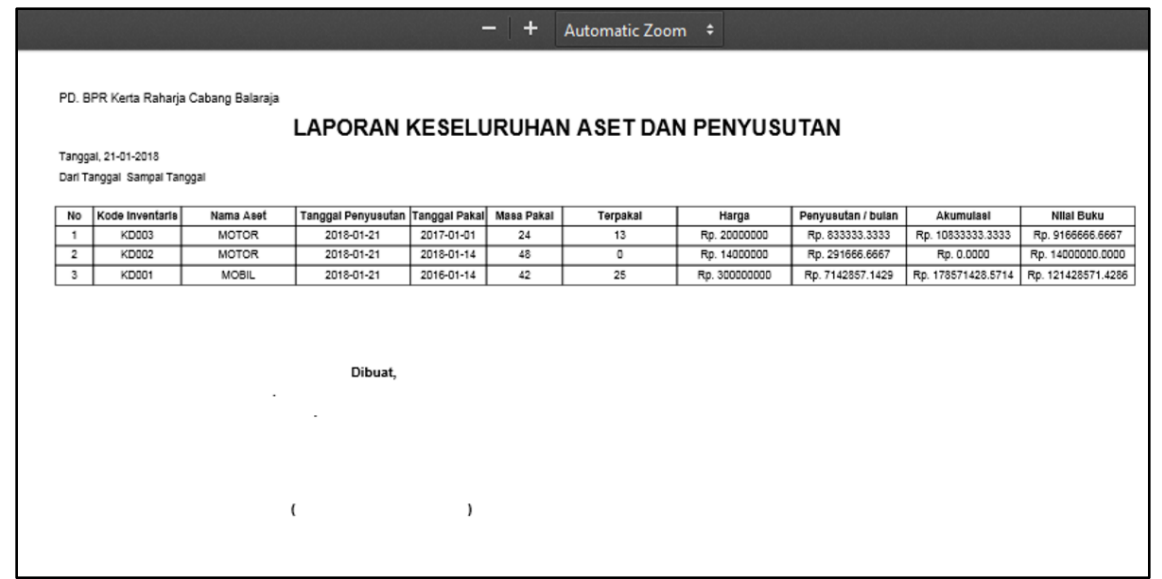

Gambar 8. Tampilan Web Menu Laporan Keseluruhan

Dengan adanya kemajuan teknologi yang sangat pesat, kebutuhan suatu sistem penunjang kinerja harus dibuat agar dapat mengurangi human error agar tidak terjadi data yang menyimpang. Manajemen Aset Berbasis Web merupakan software yang dapat membantu pemasukkan dan pengeluaran data secara efisien tanpa harus membuka lembaran worksheet yang membutuhkan waktu lama.

Dengan adanya permasalahan tersebut dalam kemudahan memberikan informasi, maka rumusan masalah dalam penelitian ini adalah bagaimana merancang sebuah sistem informasi yang dapat login dengan menggunakan Web pada sistem Manajemen Aset yang dapat di akses secara publik. 
Setelah mengamati dan meneliti dari beberapa permasalahan yang terjadi pada sistem yang berjalan terdapat beberapa alternatif pemecahan masalah yaitu dengan membangun dan merancang serta login dengan Web untuk memudahkan seseorang memperoleh informasi yang berkaitan dengan sistem Manajemen Aset dan mampu mendapatkan informasi lebih efisien dan efektif.

Setelah kelayakan program telah diketahui, maka langkah selanjutnya dilakukan implementasi program pada PD.BPR Kerta Raharja Cabang Balaraja, implementasi program berlangsung selama satu minggu.

\section{KESIMPULAN}

Berdasarkan analisa sistem manajemen aset di PD.BPR Kerta Raharja Cabang Balaraja yang telah dijelaskan di atas maka dapat diambil kesimpulan sebagai berikut :

1. Sistem informasi manajamen aset pada PD.BPR Kerta Raharja Cabang Balaraja yang sedang berjalan saat ini terdapat kendala-kendala yang menyulitkan user, proses penginputan masih dilakukan secara semi komputer dengan menggunakan Ms. Excel.

2. Kebutuhan user terhadap sistem informasi manajemen aset pada PD.BPR Kerta Raharja telah diidentifikasi melalui tahapan User Requirement, terdiri dari 33 kebutuhan fungsional dan kebutuhan nonfungsional.

3. Sistem informasi manajemen aset berbasis web dirancang agar dapat mempermudah admin dalam penginputan data aset, data penyusutan aset dan pembuatan laporan aset.

\section{SARAN}

Dengan mengamati penelitian manajemen aset di PD.BPR Kerta Raharja Cabang Balaraja mulai dari pendataan dan pembuatan laporan, maka dalam penyusunan Skripsi ini diberikan saran antara lain sebagai berikut :

1) Sistem yang dirancang masih bersifat independen. Oleh karena itu, perlu dilakukan pengembangan lebih lanjut agar dapat terintegrasi dengan sistem informasi lain.

2) Perlu adanya pengembangan terhadap aplikasi ini mengingat masih banyak pekerjaanpekerjaan seperti pengadaan aset, peminjaman dan pengembalian aset. 
3) Perlu pembuatan scan dan print barcode barang sehingga lebih memudahkan dalam input aset.

\section{DAFTAR PUSTAKA}

Daftar pustaka harus memuat keseluruhan dari sumber referensi yang dirujuk dalam teks. Derajat kemutakhiran pustaka yang diacu adalah 10 tahun terakhir, karya klasik yang relevan dapat diacu sebagai sumber masalah tetapi tidak untuk perbandingan pembahasan. Penulisan daftar pustaka mengikuti acuan yang berlaku umum. Pada bagian ini diisi dengan pustaka yang digunakan pada penelitian, dan tulis dengan urutan pengutipannya, dengan format penulisan APA (American Psychologycal Association), dengan contoh penulisan pustaka seperti dibawah ini;

[1] Adi, Sumaryadi. 2014. Onlinekan!: Memulai Membangun Website Istimewa. Bandung: Azzahra Publishing.

[2] Alviyanto, Fransiskus Eferdy. 2014. Perancangan Website Dosen Jurusan Sistem Informasi pada STMIK Raharja. Skripsi. Tangerang: STMIK Raharja.

[3] Amrullah, Agit. dkk. 2016. Kajian Kebutuhan Perangkat Lunak Sistem Informasi Penilaian Prestasi Kerja Pegawai Pada Fakultas Adab dan Ilmu Budaya Universitas Islam Negeri Sunan Kalijaga Yogyakarta. Seminar Nasional Teknologi Informasi dan Multimedia 2016 ISSN: 2302-3805.

[3] Anhar. 2016. Kumpulan Source Code Visual Basic 6.0 untuk Skripsi. Jakarta: PT. Elex Media Komputindo.

[5] Budianto dkk. 2015. Aplikasi Monitoring Sistem Absensi Sidik Jari Sebagai Pendukung Pembayaran Biaya Pegawai Terpusat Dengan SAP. Jurnal CCIT Vol.8 No.3. Tangerang: STMIK Raharja.

[6] Chan, Syahrial. 2017. Membuat Aplikasi Database dengan PowerBuilder 12.6 dan MySQL. Jakarta: PT. Elex Media Komputindo. 
[7] Desai, Prashant Ramchandra. A Survey of Performance Comparison between Virtual Machines and Containers. International Journal of Computer Sciences and Engineering (IJCSE) Vol. 4 Issue 7 E-ISSN: 2347-2693.

[8] Ginting, Elizaandayni. 2013. Aplikasi Penjualan Berbasis Web (E-Commerce) Menggunakan Joomla pada Mutiara Fashion. Skripsi. Bandung: Universitas Widyatama.

[9] Haryanto, Dadang. Dede Koswara. 2015. Perancangan Sistem Informasi Akuntansi Terintegrasi PT Petrokimia. (Studi Kasus Di Toko/ Kios). 